\title{
Dialysis efficacy and pain levels in relation to cannulation distance using the buttonhole technique
}

\author{
Öznur Kal ${ }^{1}$, Enes Duman ${ }^{2}$ and Ali Kal ${ }^{3^{*}}$
}

\begin{abstract}
Objective: In this study, we investigated whether there was any difference in pain and dialysis efficacy when patients who initially entered dialysis with the rope ladder technique were switched to the buttonhole technique.

Methods: We reduced the space between needles and examined the effects on access blood flow rate, dialysis efficacy, and pain levels with BH technique. Forty-four patients participated, 25with dialysis needles placed 5-7 cm apart using the $\mathrm{BH}$ technique, and 19 with needles placed $7-10 \mathrm{~cm}$ apart.
\end{abstract}

Results: There was a significant reduction in the pain sensation in both groups from patients who passed the rope ladder technique to the buttonhole technique from the onset to the sixth month. There was no difference in dialysis efficacy between the patients who passed the lope ladder technique to the buttonhole technique; also, there was no difference in the dialysis efficacy compared to the needle entry interval in two groups of patients who were dialyzed with the $\mathrm{BH}$ technique.

Discussion: The BH technique continues to attract interest due to its dramatically reduced pain levels compared to the $R L$ technique and no difference in dialysis efficacy.

Keywords: Arteriovenous fistulas, Access blood flow rate, Cannulation pain

\section{Introduction}

It is essential to establish and maintain appropriate vascular access in haemodialysis (HD) patient [1]. Arteriovenous fistulae (AVF) are recommended by many national clinical guidelines as the vascular access of choice for HD patients with end-stage kidney disease [2]. The traditional type of AVF puncture is the rope-ladder (RL) technique. Another method, the buttonhole (BH) or constant-site technique, uses the same AVF cannulation sites for every dialysis session with the aim of minimising venous damage [3]. The $\mathrm{BH}$ puncture method is considered a good alternative to RL and is currently recommended by several scientific societies, including the National Kidney Foundation/Kidney

\footnotetext{
* Correspondence: dralikal@yahoo.com

${ }^{3}$ Department of Ophthalmology, Başkent University Hospital, Konya, Turkey Full list of author information is available at the end of the article
}

Disease Outcomes Quality Initiative (NKF/KDOQI) and the European Vascular Access Society [4]. BH needling was initially popular for home HD, but its use has spread to include clinical centre dialysis. The technique requires the creation of a single tract using a standard sharp fistula needle, which can then be accessed using a blunt needle at the same entry site and tract each time. The main advantages reported for the $\mathrm{BH}$ technique include easier AVF cannulation, fewer puncture failures, less pain, more rapid haemostasis after needle removal and fewer aneurysms and haematomas [5]. However, several studies have shown a higher rate of infection associated with $\mathrm{BH}$ fistula access compared to sharp needle puncture techniques [6]. Recent systematic reviews have concluded that $\mathrm{BH}$ cannulation may be associated with a higher rate of local infection and bacteraemia compared to area puncture needling, but more 
definitive studies are required to reach firm conclusions $[7,8]$, as some studies have not noted increased systemic infections from $\mathrm{BH}$ needling [9].

Observational studies have failed to prove a longer fistula survival time for the $\mathrm{BH}$ technique compared to standard RL needling $[9,10]$. In this study, we wanted to compare the cannulation pain levels and dialysis activities between the rope ladder technique and the buttonhole technique. We also distinguished the patients using the buttonhole technique, two groups according to the distance of the cannulation points. We compared their pain values and dialysis activities.

We investigated several parameters, such as vascular area blood flow rate (BFR) between the needles, dialysis venous pressure (DVP), dialysis adequacy $(\mathrm{Kt} / \mathrm{V})$, pain during cannulation and the distance between needles. Patients with AVF were placed into two groups according to entry points. We compared patients with fistula needles spaced from $5-7 \mathrm{~cm}$ to those with spaced from $7-10 \mathrm{~cm}$ in terms of pain sensitivity and dialysis efficacy.

\section{Material and methods}

This study was approved by the Baskent University Institutional Review Board and Ethics Committee (project no: KA15/170). The research adhered to the tenets of the Declaration of Helsinki, and a detailed written informed consent form was obtained prior to each individual's participation in the study. We designed a prospective single-centre crossover study to compare the $\mathrm{BH}$ and $\mathrm{RL}$ cannulation methods for 1 year in 44 stable HD patients with end-stage renal disease undergoing regular $\mathrm{HD}$ in the Haemodialysis Unit at Baskent University Konya Hospital. Eligible individuals were over 18 years of age and had received $\mathrm{HD}$ three times weekly, $4 \mathrm{~h}$ per session, for at least 6 months prior and had mature AVFs used for RL cannulation.

In the study, $\mathrm{BH}$ tunnel tracts were established for all the patients. Three patients were excluded from the study due to prolonged bleeding in the fistula whilst starting the buttonhole cannulation. In patients undergoing the RL technique in previous sessions, a tunnel line was created for the $\mathrm{BH}$ technique by the selected nurses at the beginning of the study which were experienced in cannulation access. Pain sensitivity and dialysis efficacy were investigated according to the distance between cannulation points after the tunnel was established. Haemodialysis patients who had no problem with their fistulas were included in the study. All patients understood the purpose of this study, and there were no problems with communication. Using local anaesthetic agents during cannulation might reduce the pain, but it was not cost effective. The patients were informed about the study and their approval was obtained. The exclusion criteria were AV grafts or central venous catheters, an infection on the fistula line, skin disease over or around the access point, a need for interventions due to AVF dysfunction, and the inability to tolerate $>300 \mathrm{ml} /$ min of blood flow during HD. The blood flow rate (BFR) of the HD machine was maintained at $300 \mathrm{ml} / \mathrm{min}$, and the perfusion rate of the dialysis solution was $500 \mathrm{ml} /$ min. Heparin was used for anticoagulation during HD.

To form the tunnel line, six to nine cannulations were made by the same nurse for the same patient. The skin at the cannulation site was cleaned with alcohol and betadine, and two 16-gauge sharp needles were inserted at $20-45^{\circ}$ angles [11]. The arterial cannulation site was placed in the more distal segment of the access but at least $3 \mathrm{~cm}$ from the $\mathrm{AV}$ anastomotic site. A venous needle was inserted at a minimum distance of $5 \mathrm{~cm}$ proximal to the arterial needling site to avoid the previous cannulation site.

The patients were divided into two groups according to the distance between the arterial and venous needle points. The diameter of the area between the arterial and venous cannulation sites was $5-7 \mathrm{~cm}$ in 25 patients (group 1) and $7-10 \mathrm{~cm}$ in the remaining 19 patients (group 2). After six to nine cannulations with sharp needles, two pairs of tunnel tracts for the $\mathrm{BH}$ method were established at the venous and arterial needling sites [12]. After six to nine dialysis sessions, the same nurse inserted 16-gauge blunt needles at $25^{\circ}$ angles for the $\mathrm{BH}$ technique. Needles were inserted using the classical method, with the arterial set directed towards the extremity of the arm, and the venous set directed towards the heart. The distance between the needles was measured with a ruler.

Vascular access BFR in the area between the needles (AVF BFR), Kt/V and DVP were measured during the first week and at the end of the 12th month study period. All patients underwent colour Doppler examinations with a EUP-L535 (Hitachi, Tokyo, Japan). Ultrasonography was performed with the patients in the supine position at 7.5 MHZ (Hitachi, EZU-MT 24-51, Tokyo, Japan) during haemodialysis. Silica gel was placed on a superficial probe, and the Doppler velocity was measured. Speed measurements were made through the dialysis needle entry points at appropriate angles. The normal range of vascular access flow (BFR) was defined as $600-1200 \mathrm{ml} / \mathrm{min}$ [5]. DVP was measured within $5 \mathrm{~min}$ after starting dialysis to prevent ultrafiltration effects. The normal DVP range was defined as $<100 \mathrm{mmHg}$. DVP values over $100 \mathrm{mmHg}$ or a gradual increase suggested recirculation [11]. As an indicator of dialysis efficiency, $\mathrm{Kt} / \mathrm{V}$ was measured using a single-pool urea kinetic model [13]. The normal range was defined as $\geq 1.4$ according to the NKF-KDOQI guidelines [13]. Pain associated with needle insertion was measured at baseline, 6 and 12 months using a 10-point visual analogue scale, with 0 indicating no pain and 10 indicating severe pain. 
$\mathrm{Kt} / \mathrm{V}$ was measured at baseline and at the 12th month. The HD dose is quantified by $\mathrm{Kt} / \mathrm{V}$, which measures urea removal during treatment, and a single-pool KT/V of 1.2 is considered an adequate dose [14]. The primary data from the National Cooperative Dialysis Study showed that the $\mathrm{Kt} / \mathrm{V}$ of $<0.8$ was associated with high mortality, whereas $\mathrm{Kt} / \mathrm{V}$ values between 1.0 and 1.2 were associated with better outcomes [15]. El-Sherikh et al. found that low recirculation percentages result in improved dialysis effect. The differences in the Kt/V values amongst these recirculation groups were statistically significant [16].

\section{Statistical analysis}

Statistical data were analysed using SPSS version 21.0 (SPSS, Chicago, IL, USA). Values were expressed as mean \pm standard deviation. The normality of the values was analysed using Kolmogorov-Smirnov test. Student's $t$ test was used according to Kolmogorov-Smirnov test results. Differences were considered significant at $p<0.05$. Correlations between the variables were investigated based on Pearson or Spearman correlation coefficient.

\section{Results}

The mean age of the patients in this study was 66.6 years, and $50 \%$ were men. The distribution of the patients according to disease aetiology was as follows: 18 with diabetic nephropathy (40.909\%), 15 with hypertensive nephropathy (34.09\%), six with glomerulonephritis $(13.63 \%)$ and five with amyloidosis $(11.36 \%)$. The mean duration of AVF access was 38.09 months. As expected the average pain in the $\mathrm{BH}$ technique was less than the RL technique. There was a significant difference between the three pain scale measurements at 0,6 and 12 months $(p<0.05$, multiple variance analysis). There was a significant decrease in pain measurements from 0 month (pain measurement of 6.5682/10) to 6 months (pain measurement of $4.5909 / 10$ ), to 12 months (pain measurement of 3.2727/10) $(p<0.05$, paired $t$ test) (Fig. 1).

The $\mathrm{Kt} / \mathrm{V}(1)$ value at the beginning of the study was calculated using the rope ladder technique. At the end of the study, the $\mathrm{Kt} / \mathrm{V}(2)$ value was calculated based on the buttonhole technique.

There was no difference between the first (1) and second (2) measurements in terms of dialysis efficacy, with a $\mathrm{Kt} / \mathrm{V}(1)$ of $1.48 \pm 0.33$ and a $\mathrm{Kt} / \mathrm{V}(2)$ of $1.49 \pm$ 0.22 ( $p=0.82$, paired $t$ test). There was no correlation between $\mathrm{Kt} / \mathrm{V}$ values for the first and second measurements relative to pinhole distance. The $\mathrm{Kt} / \mathrm{V}$ values of the first measurement using the RL method and the last measurement using the $\mathrm{BH}$ method were not significantly different (Fig. 2). The distance between needle punctures was significantly shorter in the diabetic patients: $1.3 \pm 0.47$ compared to $1.61 \pm 0.5$ in non-diabetic patients ( $p=0.047$, Student's $t$ test).

The measurement of blood flow velocities in the AV fistula areas of the patients were checked before and at the end of the study. There was a significant difference between Doppler 1 and 2 measurements in blood flow velocity in the area between the drainage holes: Doppler $1=95.56 \pm 36.43$, Doppler $2=106.86 \pm 37.94$ (the change in needle puncture distance was correlated with the effects of Doppler 1 and 2 ( $p<0.05$, paired $t$ test). There was a positive correlation between the Doppler flow difference in the cannulation area BFR and DVP ( $p$

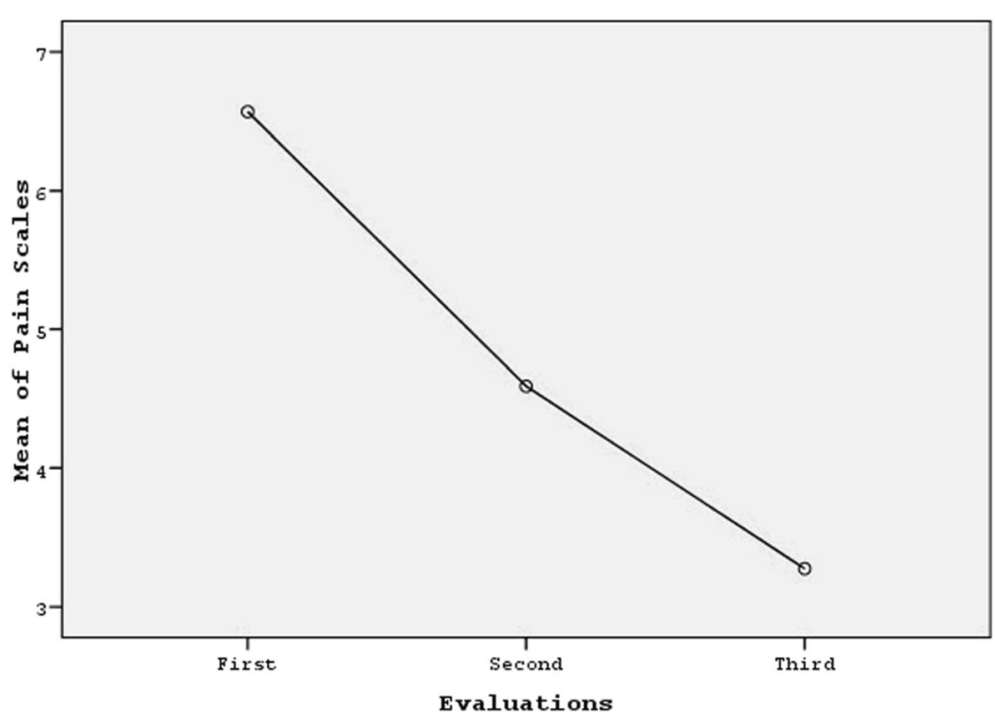

Fig. 1 Time course of pain scale: first (0), second (6) and third (12th month) pain levels (change in pain level when switching from robe ladder technique to buttonhole technique) 


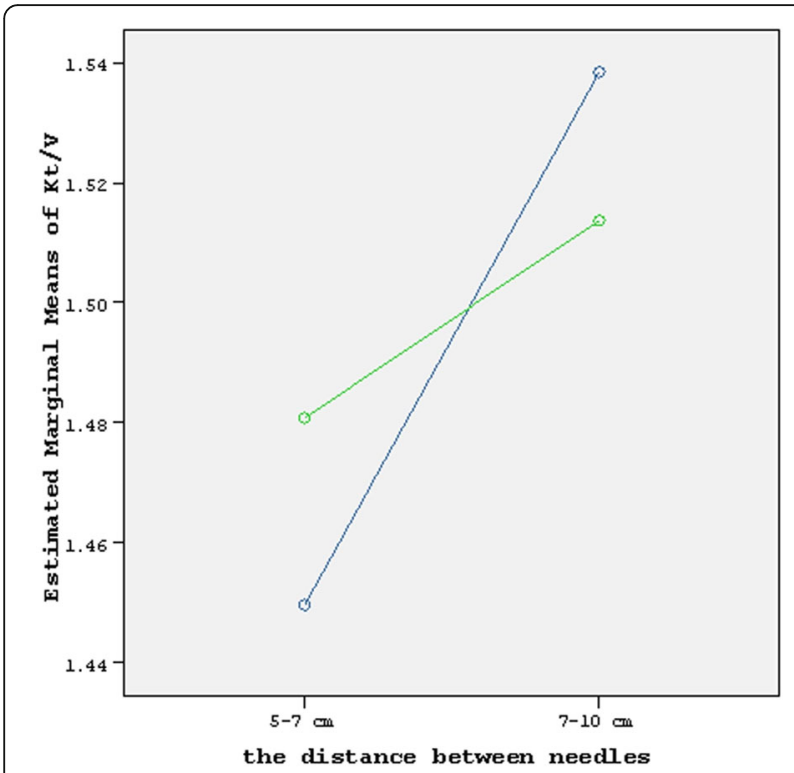

Fig. 2 Percentage of Kt $N$ urea according to needle-puncture distance of patients entering dialysis in $\mathrm{BH}$ technique. Change in $\mathrm{Kt} / \mathrm{N}$ value according to cannulation distance in buttonhole technique $(p=0.82)$

$=0.009, r=0.387$, Pearson's correlation test) (Fig. 3). Cannulation distance had a significant effect on the BFR difference (multiple variance analysis, $p=0,031$ ). As the cannulation distance decreased, the flow velocity in the Doppler increased. This difference can be explained by the increase in recirculation as the cannulation distance decreases. This difference is shown in Fig. 3.

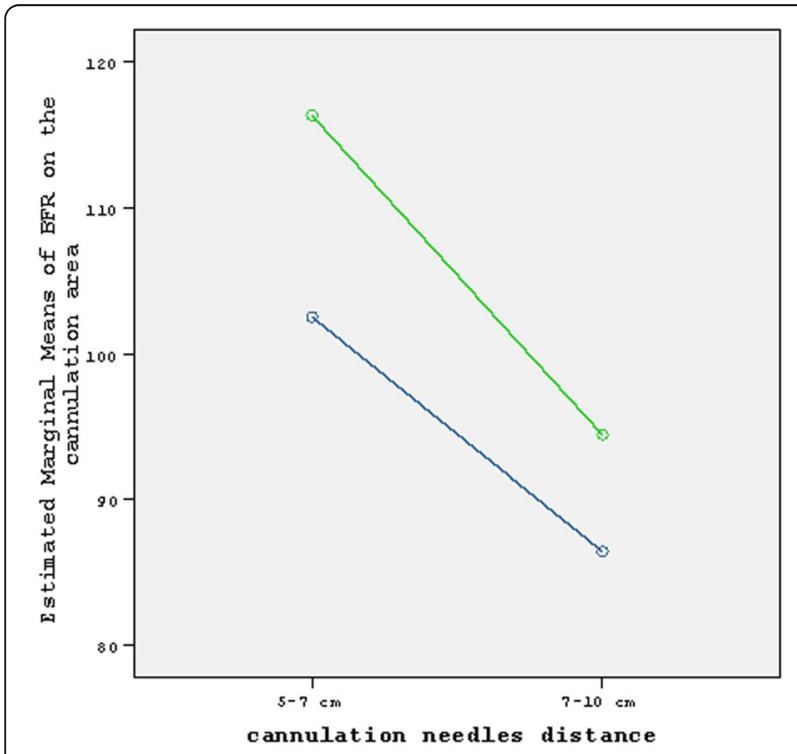

Fig. 3 The relationship between needle puncture distance and BFR (blood flow rate- $\mathrm{ml} / \mathrm{min}$ ) in the cannulation area. Change in BFR by cannulation distance over the course of the study $(p<0.05)$

\section{Discussion}

Research on long-term $\mathrm{BH}$ cannulation has shown that pain is reduced over time using this technique. Pain is the most common complaint of HD patients during RL cannulation using sharp needles [13]. It is the main reason for refusal to undergo dialysis, and it reduces the patient's quality of life. The success of arteriovenous fistula cannulation is dependent on many variables. One of these variables includes the length of vascular access available to accommodate two needles [17]. Effective haemodialysis is directly related to a better health condition, lower morbidity and mortality rates for haemodialysis patients. But a good quality of dialysis is provided by a series of factors, amongst them the technique of AVF puncture and the amount of blood recirculation. Blood recirculation occurs when the rate of access flow becomes lower than the rate of dialyzer blood flow especially in the presence of inadequate location of the needles inserted into the AVF [18]. BH cannulation has been shown to be a simple and cost-effective alternative for reducing pain compared to RL cannulation [19]. One observational study showed the $\mathrm{BH}$ technique to be associated with an increased perception of pain; van Loon et al. showed that the average pain score in patients undergoing the $\mathrm{BH}$ technique was greater than patients undergoing the RL method [5], these findings are not consistent with other studies, including the present one, in which pain was decreased with BH cannulation compared to the RL method, with significant differences between the three pain-scale measurements $(p<0.05)$. In contrast to the studies showing that the $\mathrm{BH}$ technique is less painful, findings were obtained in two randomised studies. Vaux et al. and Mac Rae et al. attributed more pain in the $\mathrm{BH}$ technique to the application of home haemodialysis and more frequent cannulation [20, 21]. Additionally, whilst the distance between the needles should be a minimum of $10 \mathrm{~cm}$ for cannulation in the $\mathrm{RL}$ technique, there is no such inquirement in the $\mathrm{BH}$ technique [5]. For patients with a very low pain threshold, the $\mathrm{BH}$ technique can be an attractive alternative. However, there was also a significant difference between the pain levels $(p<0.05)$, suggesting that pain gradually diminished when a patient was switched to the $\mathrm{BH}$ technique after being previously dialysed with the RL technique (Fig. 1).

In our study, patients originally underwent HD using the RL technique and then received $\mathrm{HD}$ with the $\mathrm{BH}$ technique for 1 year. At the end of this period, there was no difference in dialysis efficacy between the two cannulation techniques. The patients who received dialysis with the $\mathrm{BH}$ technique were also divided into two groups according to pinhole distance, with fistula needle spacing of either $5-7 \mathrm{~cm}$ or $7-10 \mathrm{~cm}$. Kt/V ratios were compared between these two groups at baseline and at 
12 months, and there was no significant difference in terms of dialysis efficacy over time $(p=0.82)$ (Fig. 2).

A similar study was performed by Rothera et al., who showed that an AVF can be cannulated with needles 2.5 $\mathrm{cm}$ apart, with no cases of access recirculation [17]. We planned the present study differently, using patients entering dialysis with the $\mathrm{BH}$ technique, as studies on tunnelled patients could not be found in the literature. Dias et al. investigated fistula cannulation techniques and found that needles placed unidirectionally and $<5$ $\mathrm{cm}$ apart were associated with more access recirculation and lower $\mathrm{Kt} / \mathrm{V}$ than with other combinations; the arterial set directed towards the extremity of the arm and the venous set directed towards the heart was the preferred technique for needle insertion at a distance of $\geq 5 \mathrm{~cm}$ [18].

For each HD treatment, the fistula is cannulated, usually with two needles. The arterial needle allows the blood to be withdrawn from the patient into the dialysis circuit, and then it is returned through the venous needle. Studies generally state that there should be a minimum of $5 \mathrm{~cm}$ between these needles to prevent or minimise blood access recirculation in order to provide efficient HD treatment [17]. The success of AVF cannulation is dependent on many variables, including the length of vascular access available to accommodate two needles. Therefore, if the fistula cannulation distance is, for example, $2.5 \mathrm{~cm}$, an alternative access route for dialysis can be sought.

Santoro concluded that the form of needle insertion and the distance between the needles should be considered in the process of recirculation reduction, with the classical form providing the lowest percentages of access recirculation and with unidirectional needles providing satisfactory results with $\mathrm{a} \geq 5 \mathrm{~cm}$ distance between them [22]. The $\mathrm{BH}$ technique is generally easier than RL and is widely used in home dialysis where self-cannulation is performed, and can only be used for native AVF [23].

Kim et al. showed that there were no statistical differences in vascular access BFR, DVP and $\mathrm{Kt} / \mathrm{V}$ between the $\mathrm{RL}$ and $\mathrm{BH}$ methods; however, cannulation pain was decreased with $\mathrm{BH}$ compared to $\mathrm{RL}$ [24]. Kt/V values using the RL method at the beginning of their study and in the last week using the $\mathrm{BH}$ method were not significantly different; this result is similar to our findings (Table 1).

When we measured Doppler flow in the area between needle entry points, the initial measurements were higher after 12 months, and the Doppler BFR in the area between the needles increased over time. There was a positive correlation between Doppler BFR and DVP (Fig. 3).

The correlation between DVP and blood flow velocity can be interpreted as the risk of recirculation increasing with decreased fistula needle distance. Consistent with previous studies [18], recirculation may occur in AVFs
Table 1 Descriptive statistics. Kt/N and needle distance

\begin{tabular}{lllll}
\hline & Needles distance & Mean & Std. deviation & $\boldsymbol{N}$ \\
\hline Kt $/ \mathrm{N}$ urea first & $5-7 \mathrm{~cm}$ & 1.4496 & 0.36151 & 25 \\
& $7-10 \mathrm{~cm}$ & 1.5384 & 0.29203 & 19 \\
& Total & 1.4880 & 0.33260 & 44 \\
Kt/N urea second & $5-7 \mathrm{~cm}$ & 1.4808 & 0.23750 & 25 \\
& $7-10 \mathrm{~cm}$ & 1.5137 & 0.20307 & 19 \\
& Total & 1.4950 & 0.22140 & 44 \\
\hline
\end{tabular}

as this distance becomes shorter. In our study, the cannulation points and the distance between the needles had significant effects on Doppler flow velocity; as needle distance decreased, blood flow velocity in the region increased. Although there was no difference in efficacy when transitioning to the $\mathrm{BH}$ technique, pain levels were dramatically reduced in the present study, more research is needed on the $\mathrm{BH}$ technique, as it seems to increase the risk of recirculation (Table 2).

This study had some limitations. It was carried out in a single centre. In addition, we only observed ideal, wellfunctioning AVFs that were easily cannulated by nurses

Table 2 Comparison of demographics and comorbidities of the study population

\begin{tabular}{|c|c|}
\hline Age & $66.56 \pm 10.95$ \\
\hline Sex & 22 male, 22 female \\
\hline Duration of haemodialysis & $41.18 \pm 40.63$ \\
\hline \multicolumn{2}{|l|}{ Disease aetiology } \\
\hline Diabetic nephropathy & 18/44 (40.90\%) \\
\hline Hypertensive nephropathy & 15/44 (34.09\%) \\
\hline Glomerulonephritis & 6/44 (13.63\%) \\
\hline Amyloidosis & 5/44 (11.36\%) \\
\hline MIS & $16.13 \pm 7.3$ \\
\hline BMI & $26.37 \pm 4.92$ \\
\hline CRP & $27.14 \pm 36.93$ \\
\hline Albumin & $3.62 \pm 0.4$ \\
\hline \multicolumn{2}{|l|}{ Creatinin } \\
\hline First & $8.04 \pm 2.63$ \\
\hline Last & $7.42 \pm 2.45$ \\
\hline \multicolumn{2}{|l|}{$\mathrm{Hgb}$} \\
\hline First & $11.28 \pm 1.13$ \\
\hline Last & $11.42 \pm 1.16$ \\
\hline \multicolumn{2}{|l|}{$\mathrm{Kt} / \mathrm{N}$} \\
\hline First & $1.48 \pm 0.33$ \\
\hline 6. month & $1.49 \pm 0.22$ \\
\hline \multicolumn{2}{|l|}{ Pain scale } \\
\hline 1 & $6.56 \pm 2$ \\
\hline 2 & $4.59 \pm 1.89$ \\
\hline 3 & $4.5 \pm 8.76$ \\
\hline
\end{tabular}


who were experienced in using these cannulation techniques. $\mathrm{BH}$ is useful in patients with AVF in whom multiple cannulation sites are absent. Therefore, the fistula entry points of all patients were set to be between $5-10 \mathrm{~cm}$ and healthy fistulas that were not experiencing any problems before included in the study.

Cannulation of the AVF in today's HD population is more difficult and abrasive than ever.

Our study has shown that the $\mathrm{BH}$ technique may be preferred because it is less painful, does not differ from the RL method in efficacy and can be applied to shorter vasculature.

Successful and painless fistula cannulation requires the dialysis nurse to be experienced and skilled. Quality and effective dialysis services in terms of patients bring patient satisfaction. If all these conditions occur, we think that the dialysis patient will be easier to adjust and haemodialysis treatment will be more successful.

\section{Conclusions}

The $\mathrm{BH}$ technique continues to attract interest due to its dramatically reduced pain levels compared to the RL technique and no difference in dialysis efficacy. We think that this technique is especially important for patients with vascular problems, as the same entry points are always used in the buttonhole technique. We believe that different studies are needed to assess different cannulation distances in terms of pain and efficacy in these patients.

Larger, more definitive studies are needed to determine whether this technique is safe for broader use.

\section{Abbreviations}

HD: Haemodialysis; AVF: Arteriovenous fistulae; RL: Rope-ladder; BH: Buttonhole; NKF/KDOQI: National Kidney Foundation/Kidney Disease Outcomes Quality Initiative; BFR: Blood flow rate

\section{Acknowledgements}

Not applicable.

\section{Authors' contributions}

OK, ED and AK mainly undertook this review. The literatures were screened by OK and ED. AK and OK participated in the design of the study and performed the statistical analysis. All patients underwent colour Doppler examinations by ED. All authors read and approved the final manuscript.

\section{Funding}

Not applicable.

\section{Availability of data and materials}

Please contact the authors for data requests.

\section{Ethics approval and consent to participate}

This study was approved by the Baskent University Institutional Review Board and Ethics Committee (project no: KA18/04). The research adhered to the tenets of the Declaration of Helsinki, and a detailed written informed consent form was obtained prior to each individual's participation in the study.

\section{Consent for publication}

Not applicable.

\section{Competing interests}

The authors declare that they have no competing interests.

\section{Author details}

${ }^{1}$ Department of Nephrology, Başkent University Hospital, Konya, Turkey. ${ }^{2}$ Department of Radiology, Başkent University Hospital, Konya, Turkey.

${ }^{3}$ Department of Ophthalmology, Başkent University Hospital, Konya, Turkey.

Received: 16 April 2020 Accepted: 22 September 2020

Published online: 06 October 2020

\section{References}

1. Knatole B, Deborah B. Improving arteriovenous fistula construction: fistula first initiative. Hemodial Int. 2004;8(3):199-206.

2. Fluck R, Kumwenda M. Renal association clinical practice guideline on vascular access for haemodialysis. Nephron Clin Pract. 2011;118(Suppl 1): 225-40

3. Twardowski Z, Lebek R, Kubara H. 6-year experience with the creation and use of internal arteriovenous fistulae in patients treated with repeated hemodialysis. Pol Arch Med Wewn. 1977;57(3):205-14.

4. NFK-KDOQI Clinical Practice Guidelines and Clinical Practice Recommendations. 2006 Updates. Available at http://www.kidney.org/ professionals/KDOQI/guideline_upHD_PD_VA_rec3.htm. Accessed 6 Jan 2016

5. Van Loon MM, Goovaerts T, Keessels AG, Van der Sande FM, Tordoir JH. Buttonhole needling of hemodialysis arteriovenous fistulae results in less complications and interventions compared to the rope-ladder technique. Nephrol Dial Transplant. 2010;25(1):225-30.

6. Macrae JM, Ahmed SB, Hemmelgarn BR, Alberta Kidney Disease Network. Arteriovenous fistula survival and needling technique: long-term results from a randomized buttonhole trial. Am J Kidney Dis. 2014;63(4):636-42.

7. Wong B, Muneer M, Wiebe N, Storie D, Shurraw S, Pannu N, et al. Buttonhole versus rope ladder cannulation of arteriovenous fistulas for hemodialysis: a systematic review. Am J Kidney Dis. 2014;64(6):918-36.

8. Grudzinski A, Mendelssohn D, Pierratos A, Nesrallah G. A systematic review of buttonhole cannulation practices and outcomes. Semin Dial. 2013;26(4): 465-75

9. Muir CA, Kotwal SS, Hawley CM, Polkinghorne K, Gallagher MP, Snelling P, et al. Buttonhole cannulation and clinical outcomes in a home hemodialysis cohort and systematic review. Clin J Am Soc Nephrol. 2014;9(1):110-9.

10. Kandil H, Collier S, Yewetu E, Cross J, Davenport A. Arteriovenous fistula survival with buttonhole (constant site) cannulation for hemodialysis access. ASAIO J. 2014;60(1):95-8.

11. National Kidney Foundation. Clinical practice guidelines for vascular access. Am J Kidney Dis. 2006;48:176-247.

12. Labriola $L$, Jadoul M. Moderator's view: buttonhole cannulation of arteriovenous fistulae; great caution is warranted. Nephrol Dial Transplant. 2016;31(4):530-3.

13. National Kidney Foundation. Clinical practice guidelines for hemodialysis adequacy. Am J Kidney Dis. 2006;48(3):12-23.

14. Eknoyan G, Beck GJ, Cheung AK, Daugirdas JT, Greene T, Kusek JW, et al. Effects of dialysis dose and membrane flux in maintenance hemodialysis. $\mathrm{N}$ Engl J Med. 2002;347(25):2010-9.

15. Gotch FA, Sargent JA. A mechanistic analysis of the national cooperative dialysis study (NCSD). Kidney Int. 1985;28(3):526-34.

16. El-Sheikh M, El-Ghazaly G. Assessment of hemodialysis adequacy in patients with chronic kidney disease in the hemodialysis unit at Tanta University Hospital in Egypt. Indian J Nephrol. 2016;26(6):398-404

17. Rothera C, Mccallum C, Huang S, Heidenheim P, Lindsay MR. The influence of between-needle cannulation distance on the efficacy of hemodialysis treatments. Hemodial Int. 2011;15(4):546-52.

18. Dias TS, Neto MM, da Costa JAC. Arteriovenous fistula puncture: an essential factor for hemodialysis efficiency. Ren Fail. 2008;30(9):870-6.

19. Figueiredo $A E$, Viegas $A$, Monteiro M. Poli de Figueiredo CE. Research into pain perception with arteriovenous fistula (avf) cannulation. J Ren Care. 2008:34(4):169-72

20. Vaux E, King J, Lloyd S, Moore J, Bailey L, Reading I, et al. Effect of buttonhole cannulation with a polycarbonate PEG on in-center hemodialysis fistula outcomes: a randomized controlled trial. Am J Kidney Dis. 2013:62:81-8.

21. Mac Rae JM, Ahmed SB, Atkar R, Hemmelgarn BR. A randomized trial comparing buttonhole with rope ladder needling in conventional hemodialysis patients. Clin J Am Soc Nephrol. 2012;7(10):1632-8. 
22. Santoro A. Confounding factors in assessment of delivered hemodialysis dose. Kidney Int. 2000;58:19-27.

23. Verhallen AM, Kooistra MP, von Jaarsveld BC. Cannulation in haemodialysis: robe-ladder or buttonhole technique? Nephrol Dial Transplant. 2007;22: 2601-4.

24. Kim M-K, Kim H-S. Clinical effects of buttonhole cannulation method on haemodialysis patients. Hemodial Int. 2013;17(2):294-9.

\section{Publisher's Note}

Springer Nature remains neutral with regard to jurisdictional claims in published maps and institutional affiliations.

Ready to submit your research? Choose BMC and benefit from:

- fast, convenient online submission

- thorough peer review by experienced researchers in your field

- rapid publication on acceptance

- support for research data, including large and complex data types

- gold Open Access which fosters wider collaboration and increased citations

- maximum visibility for your research: over $100 \mathrm{M}$ website views per year

At BMC, research is always in progress. 